\title{
EL DERECHO DE LOS PADRES A ELEGIR EL TIPO DE EDUCACIÓN QUE DESEEN PARA SUS HIJOS
}

\author{
Enrique MARCOS PASCUAL \\ INVESTIGADOR, DERECHO CONSTITUCIONAL \\ UNIVERSIDAD DE LA RIOJA
}

s $\quad$ u m a r i o

I. Antecedentes en nuestra historia político constitucional. II. Los debates constituyentes III. El contenido del derecho. IV Limites del derecho. V. El derecho de los padres a elegir y el criterio de admisión. VI. El Cheque escolar en el sistema educativo español. VII. Conclusiones.

\section{r e $\quad$ s $u$ m e $\quad n$}

El derecho de los padres a que sus hijos reciban la educación de acuerdo con sus convicciones, está implicando en el seno de una sociedad plural, un derecho de elección, derecho que se conecta con la libertad de creación de centros docentes, de forma tal que se posibilite a los padres la elección del centro que se adecue a sus creencias e ideario, lo que no supone, ni puede suponer, el derecho a imponer a los demás las propias convicciones, ni la posibilidad de exigir un determinado trato diferencial en función de tales convicciones, con lo que no se podrá imponer una diferencia de trato o discriminación positiva a partir de las propias ideas.

\section{Antecedentes en nuestra historia político constitucional}

La Constitución de I8I2 de Cádiz, dedicó a la Instrucción pública el titulo IX, integrado por los artículos que van desde el 366 al 370, donde se regulaba la generalización de las escuelas de primeras letras, las universidades, implantación del plan general uniforme, inspección administrativa de toda la enseñanza a cargo de una dirección general de estudios, y las funciones de planificación y ordenación encomendadas a las Cortes que era el órgano competente para el conocimiento de la enseñanza, denominada en el texto 
instrucción pública, como ha establecido Souto en su análisis del Título IX de esta norma Constitucional ${ }^{\mathrm{I}}$. Se trata de una educación plenamente confesional, en la que la instrucción religiosa se considera como ingrediente fundamental de la instrucción, sin aparecer protegidos jurídicamente los derechos y libertades fundamentales en la materia. Argüelles critica la aprobación del Art. I2 de esta norma «se consagraba de nuevo la intolerancia religiosa y lo peor era que, por así decirlo, a sabiendas de muchos que aprobaron con el más profundo dolor el artículo i2 que consagraba que la religión de la nación Española es la católica»². Por lo demás, no hay ninguna mención al derecho de los padres a elegir el tipo de educación que deseen para sus hijos, si bien en materia de educación fue realmente liberal y progresista y un medio importante en la positivación del derecho a la educación. En palabras de Rodríguez Coarasa «es un texto que incorpora principios fundamentales de extraordinaria influencia posterior, sentando las bases de la tendencia uniformista del liberalismo español» ${ }^{3}$.

Es, hasta ahora, la única en la historia de España que ha incluido un título en exclusiva al tema de la educación, a la Instrucción Pública, más exactamente fue el título IX. En esta constitución se respeta la organización anterior de la enseñanza en España, donde sólo se recogían la educación primaria y las universidades. Aunque no cambia la estructura, si que se introducen ideas muy importantes y renovadoras para esos tiempos, como la defensa de la universalidad de la educación primaria para toda la población sin excepciones (una escuela de primeras letras en todos los pueblos de la Monarquía) para aprender a leer, escribir y contar, y la uniformidad de los planes de enseñanzas para todo el Estado. Igualmente, se señala que las competencias en educación recaen sobre las Cortes y no sobre el Gobierno. También se incluía en esta Constitución la enseñanza obligatoria del Catecismo, por lo que la libertad confesional no estaba recogida.

La ley de Instrucción pública de I857, la «Ley Moyano». Las constituciones de la etapa isabelina, incluyen todas ellas una referencia a la instrucción o a la enseñanza. El 9 de septiembre de 1857 se publica la Ley de Instrucción Pública conocida con el nombre del Ministro que la promovió y refrendó Don Claudio Moyano Samaniego. Existe en dicha Ley una alusión a la educación en familia, llamada aquí enseñanza doméstica, es reconocida en la denominada ley básica de educación. Decía la denominada Ley Moyano que «serán admitidos a los exámenes de ingreso para la segunda enseñanza los que hayan adquirido la primera en casa de sus padres, tutores o encargados de su educación, aun cuando no la hubieren recibido de Maestro con titulo» ${ }^{4}$. La enseñanza era contemplada como una cuestión de poder en la que los individuos son formados sobre la base de criterios de adoctrinamiento y respeto al orden constituido. Esta ley es el substrato sobre el que perdura toda la enseñanza en España hasta la aparición de la Ley General de Educación.

La Constitución de I869, que en su artículo 24 declararía que «Todo español podrá fundar y mantener establecimientos de instrucción o de educación, sin previa licencia, salvo la inspección de la autoridad competente por razones de higiene y moralidad». No obstante, desconoce cualquier tipo de protección jurídica directa del derecho fundamental a la educación y al derecho de los padres a la elección de centro educativo.

${ }^{\text {I }}$ Souto PAZ., J.A., «El derecho a la educación», Boletín de la Facultad de Derecho I, Madrid, p. 28.

${ }^{2}$ ARgüElles, A., Historia Crítica del pensamiento español, 8 vols, Barcelona: Círculo de Lectores I993, p. 7I.

${ }^{3}$ Rodríguez CoARASA, C., La libertad de enseñanza en España, prol. de Antonio Torres del Moral, Madrid: Tecnos, I999, p. 27.

${ }^{4}$ Sección $2^{\text {a }}$, Título III donde recoge en el art. 156, Ley de Bases aprobada por las Cortes el i7 de julio del mismo año de 1857 . 
La Constitución de I876 en su artículo i2 recogía la libertad de enseñanza, y otorgaba una reserva expresa a favor del Estado de la potestad para otorgar o expedir títulos profesionales y establecer las condiciones y formas de su obtención. Asimismo el texto de la Restauración establece el concepto de enseñanza pública subvencionada por el Estado. No reconoce en ningún artículo el derecho de los padres a la elección de centro educativo.

La Constitución de la II República, establece la famosa y polémica prohibición de ejercer la enseñanza a las órdenes religiosas, se consagra la gratuidad y obligatoriedad de la enseñanza primaria, y el deber de la República de facilitar a los más necesitados el acceso a la educación. Configura la enseñanza como un servicio público de titularidad exclusiva del Estado. No hay ninguna referencia al derecho de los padres a la elección del tipo de educación que deseen para sus hijos.

Las leyes fundamentales del reino regulan el derecho a la educación en el Art. 5 del Fuero de los españoles, en el Art. 23 de la misma ley fundamental, en el Principio IX de la ley de principios del Movimiento Nacional de I7 de mayo de 1958 , que establecen un derecho general de todos los españoles a la educación general, recogiendo claramente el derecho a la educación. La libertad de enseñanza no era declarada expresamente, aunque debía entenderse implícitamente reconocida en el Art. 5 del Fuero, dado el contexto político en la que se inserta no pasaba de ser una libertad formal que se inserta en una dictadura.

La Ley General de educación de Villar Palasí de I970, trata de llevar adelante la aplicación de las leyes fundamentales, adaptando al sistema educativo de i970. Esta ley estableció la enseñanza obligatoria hasta los I4 años con la EGB, Educación General Básica. En el contexto que se producía lo que propuso Villar Palasí con esta ley era realmente una revolución, ya que se superaba el modelo graduado con la adopción de la llamada «Educación personalizada» y las formas de trabajo en equipo. Establece que la familia tiene como deber y derecho primero e inalienable la educación de sus hijos. En consecuencia, constituye una obligación familiar, jurídicamente exigible, cumplir y hacer cumplir las normas establecidas en materia de educación obligatoria, ayudar a los hijos a beneficiarse de las oportunidades que se les brinden para estudios posteriores y coadyuvar a la acción de los centros docentes.

Recoge el derecho de los padres, y en su caso los tutores o guardadores legales, quienes tienen derecho a elegir para los menores e incapacitados los Centros docentes entre los legalmente establecidos y a ser informados periódicamente sobre los aspectos esenciales del proceso educativo.

Esta Ley quiso introducir en España, como cauce de financiación de la enseñanza privada, un modelo que parecía hacerse eco del sistema contractual francés, con la consiguiente ambigüedad en cuanto a su significado y fundamentación, como señalan Gómez-Ferrer y Ortíz Díaz, la Ley General de Educación preveía una «subvencióncompensación» así dice Gómez Ferrer «a los centros de enseñanza se les impone la educación gratuita y se les compensa en forma tal que puedan cubrir el coste del sostenimiento y la amortízación e intereses de las inversiones»s.

Por otro lado la enseñanza era libre desde el punto de vista constitucional -aún dentro de las limitaciones que para la libertad ideológica, caracterizaban al sistema- en virtud de lo que se desprendía indirectamente del artículo 5 del Fuero de los Españoles, lo que impedía su posible consideración como servicio público, en cuanto actividad prestacional (no instrumental) de exclusiva titularidad pública.

\footnotetext{
${ }^{5}$ GÓMEZ-FERRER MORANT, R., «El régimen general de los centros privados de enseñanza», Revista de Administraciones públicas 70, I973, p. 20.
} 
Importante en este periodo fue la reforma de la Ley de contratos del Estado de I973, en su artículo 2.7, y que recoge la figura del concierto escolar de la Ley General de Educación, ya que hasta ahora el concierto que recogía la LGE aparecía como un contrato de financiación, en palabras de Guaita «el Art. 2.7 aludía descaradamente a la acción concertada» ${ }^{6}$, en palabras de Mendoza Oliván «la reforma de I973 además de establecer un régimen jurídico paracontractual con respecto a la acción concertada estableció criterios válidos para definir los contratos administrativos especiales o atípicos» ${ }^{7}$. Recogía la posibilidad de concertar centros, regulando los derechos y obligaciones de las partes y tomando como baremo el número de alumnos.

Posteriormente las sucesivas Leyes de los Planes de Desarrollo, no han supuesto la desaparición de esta vieja técnica jurídica, que comentó Gallego Anabitarte «hubiera sido mejor la denominación régimen de ayudas, en lugar de la acción concertada» ${ }^{8}$.

Para finalizar y como conclusiones de este capítulo, reconocer que el derecho a la educación y la libertad de enseñanza en nuestra historia constitucional más reciente fue contradictorio, se establecen distintos modelos en las Constituciones, Leyes y que fue elemento de discrepancia en la vida política de nuestro país. Durante los siglos XIX y XX la Iglesia Católica y las órdenes religiosas tuvieron la concesión y la exclusividad de la educación. Se establece en todas las Constituciones y Leyes dos perspectivas del debate educativo, por un lado quienes consideran que es responsabilidad del Estado, al margen de las convicciones religiosas y por otro lado quienes defienden la libertad de enseñanza, y pretenden que el Estado no se interponga en la educación de la población. Destacar también la denominada «Ley Moyano» como una de las referencias en la historia del derecho a la educación y del sistema educativo español y quién otorgó una legislación estable y general.

\section{Los debates constituyentes}

Sabido es que la aprobación y discusión en las Cortes del artículo 27 de la Constitución de 1978 no fue nada sencilla. Las intervenciones de los portavoces de los distintos partidos muestran el alto grado de controversia. Todas estas controversias fueron superadas por el denominado «consenso» hasta llegar a recoger el articulado tras su discusión, elaboración y articulación. La posición de Unión de centro democrático fué la de defender que corresponde a los padres elegir el tipo de enseñanza - incluidas las convicciones religiosas, filosóficas, morales, etc. También defiende que este derecho debe ser garantizado por el Estado. Para el Partido Socialista Obrero Español la educación es sólo responsabilidad del Estado, defiende una enseñanza laica, y un pluralismo de los centros escolares. No reconoce plenamente el derecho de los padres y pone limitaciones a la libertad de creación de centros docentes. El Partido Comunista de España propugna la enseñanza

\footnotetext{
${ }^{6}$ GuAitA MARTORELl, A., «Los contratos de la Administración pública en la legislación española», Revista Internacional de ciencias administrativas I, I980, p. 67.

${ }^{7}$ Mendoza Oliván, V. «La revisión del régimen jurídico de los contratos del Estado», Revista de Hacienda pública española 2I, I973, p. 38.

Vid. también LaRrumbe Biurrúm, P., «Comentarios a la reforma del Texto Articulado de 8 de abril de I965, de Contratos del Estado, por la Ley 5/1973, de I7 de marzo», Revista de Administraciones públicas 72 , p. 342.

${ }^{8}$ GALLEgo ANABITARTE, La acción concertada: nuevas y viejas técnicas jurídicas de la Administración en Libro homenaje al Prof. Juan Galván Escutia, Valencia: Universidad de Valencia, I980, pp. I9I260.
} 
pública y única, sin negar la posibilidad de que los particulares abran escuelas privadas a sus expensas, la libertad de enseñanza se traduce en que haya unas clases de religión a las que puedan asistir los alumnos cuyos padres lo pidan expresamente. Para Alianza Popular los poderes públicos deben garantizar el derecho preferente de los padres a elegir el tipo de educación y el centro escolar al que deseen acudir sus hijos y a determinar que reciban la educación religiosa y moral que esté de acuerdo con sus convicciones, en la educación no puede prescindirse de la dimensión trascendente de la persona, y del pluralismo necesario en una sociedad pluralista. Para Esquerra Republicana de Cataluña es imprudente constitucionalizar la ayuda a centros privados y defiende el pluralismo escolar de una forma un tanto peculiar, puesto que afirman que dicho pluralismo puede crearse y mantenerse en el interior de las escuelas que dependen de los poderes públicos. El Partido Aragonés regionalista reconoce el derecho que asiste a los padres y defienden que no se puede separar la formación religiosa y la formación educativa ya que ambas son fases de la formación escolar.

En definitiva, como afirma Díaz Revorio, los partidos conservadores se preocuparon más por la libertad de enseñanza, la izquierda se concentraba en el derecho a la educación obligatoria y gratuita. ${ }^{9}$

La polémica, en el tema que nos concierne, se suscitó, de forma muy visible, en la Comisión de asuntos constitucionales y libertades públicas a propósito de las enmiendas presentadas por los Sres. Silva Muñoz y López Rodó, ambos del Grupo Parlamentario de Alianza Popular, quienes consideraron que los padres como primeros responsables de la educación de los hijos tienen el derecho a elegir el tipo de educación que deseen para sus hijos, basándose en que el fundamento de los deberes y derechos de los padres está en el propio derecho natural, anterior y prioritario al Estado.

En palabras del Sr. Silva Muñoz : «La formación integral se inicia y se estructura esencialmente en el seno de la familia, que constituye la célula básica y primaria de todo proceso educativo. Consideramos que los padres son los primeros responsables en la educación de los hijos. Es este un deber familiar ineludible que nace del derecho de los hijos a recibir enseñanza» ${ }^{\text {IO }}$. Reconoce el Diputado el derecho de los padres a elegir el tipo de educación que habrá de darse a sus hijos, de acuerdo con los dictados de su conciencia y en cumplimiento de su indeclinable responsabilidad. El fundamento de los deberes y derechos de los padres como educadores está en el propio derecho natural anterior y prioritario a los del Estado. El respeto a este valor esencial, que constituye parte de nuestra razón de ser, exige un planteamiento claro y terminante que establezca la libertad de enseñanza.

Por su parte el Sr. López Rodó de Alianza Popular defiende que los poderes públicos deben garantizar el derecho preferente que asiste a los padres de elegir para sus hijos el tipo de educación y la formación religiosa y moral que esté de acuerdo con sus propias convicciones. Se pregunta el ponente si la Declaración de derechos humanos suscrita por España reconoce este derecho preferente de los padres y este derecho concreto a escoger el tipo de educación, entonces no hay porqué quitar del texto constitucional estos dos conceptos.

Estas enmiendas fueron rebatidas por el Sr. Alzaga Villamil y Roca Junyent si bien estaban de acuerdo en el fondo de la cuestión, ya que defienden asimismo el derecho de los

9 DíAz ReVorio, F.J., «El derecho a la educación», Anuario Parlamento y Constitución, Madrid, I998, p. 269.

1o Debate en la Comisión de Asuntos Constitucionales y libertades públicas 72, 23.V.I978, p. 2598, sesión $n^{\circ}$ II de la Comisión. 
padres a elegir. El derecho civil impone a los padres la obligación de educar a los hijos, y de esta obligación deriva para aquellos el derecho a instruirles y elegir sus maestros.

Señala Alzaga Villamil «Arrebatar a los padres el derecho a educar e instruir a sus hijos equivale a esterilizar la fuerza moral de la familia» ${ }^{\text {II }}$.

El debate en el Pleno del Congreso tuvo en los parlamentarios antes citados de Alianza Popular la misma defensa, así el Sr. Silva Muñoz de Alianza Popular pidió que se recogiese en el Texto Constitucional de una manera expresa la libertad de elección del centro docente, en su intervención viene a afirmar que los padres son los primeros responsables de la educación de sus hijos.

El planteamiento en su contra lo realiza la representante del Partido Socialista Obrero Español-Partit dels Socialistas de Catalunya, Sra. Mata Garriga quién manifestó que la responsabilidad corresponde a los poderes públicos, quienes son el principal responsable de la enseñanza por encima de los padres, afirma «Lo que nos duele es que no se destaque en absoluto lo que es principio normalmente aceptado por las Constituciones Europeas, incluidos los países con tradición de problema escolar, a saber: que los poderes públicos son el principal responsable de la enseñanza» ${ }^{12}$.

Posteriormente se presentaron una serie de enmiendas que tratan sobre aspectos más formales, que modifican un término por otro, de forma verbal, etc. Así en la enmienda $\mathrm{n}^{\circ}$ 2I7 por el Sr. Cachorro Pardo de Alianza Popular, se propone sustituir «los poderes públicos» por «el Estado», la justificación es que considera que debe ser el Estado el que vele por y garantice el derecho de todos a la educación, así como velar por el cumplimiento de tales Leyes. Debe ser también el Estado quien respete y garantice el derecho preferente de los padres a elegir la educación de sus hijos. Mediante la enmienda núm. 225 el Sr. Carazo Hernández como Independiente pidió cambiar el término «garantizan» por el «garantizarán» «el derecho que asiste a los padres para que sus hijos reciban la formación religiosa y moral».

De mayor calado es la enmienda $\mathrm{n}^{\circ} 424$ presentada por la Sra. Landáburu González, Senadora por designación real, propone: «Los poderes públicos garantizan el derecho que asiste a los padres para que sus hijos reciban la formación religiosa, moral y educativa que esté de acuerdo con sus propias convicciones». Defiende así la posibilidad por parte de los padres, no sólo debe estar en la materia religiosa o moral, sino también en la puramente educativa o docente, puesto que no se puede hablar de libertad de enseñanza, si no se establece la pluralidad de opciones educativas. Mediante la enmienda núm. 577 por el Sr. Martín-Retortillo de Progresistas y Socialistas Independientes, se propone que se añada a continuación de la palabra «hijos» lo siguiente «menores de edad», basándose en que el derecho que se reconoce a los padres lo es tanto en cuanto ostentan la patria potestad, por lo que debe aludirse a los hijos menores de edad.

El Sr. Wirinacs Damiáns del Grupo Independiente aboga por un modelo de escuela estrictamente pública: «Los defensores de la escuela privada no quieren libertad de enseñanza. Quieren libertad de enseñanza para los econonómicamente fuertes, que es la cosa más antidemocrática y contraria a la libertad que pensar se pueda. Quieren escuelas de "apartheid", escuelas de la clase dominante, bien separaditos de la chusma y, encima, pagados por todos» ${ }^{\text {13 }}$.

\footnotetext{
${ }^{\text {II }}$ Loc. Cit., p. 2600 , sesión núm. in de la Comisión.

${ }^{12}$ Loc. Cit., p. 4054, sesión plenaria núm. 35

${ }^{13}$ Loc. Cit., p. I9I7, sesión núm. 6 de la Comisión.
} 
En el pleno del Senado la Sra. Landáburu González (Senadora por designación real) defiende el derecho a la elección de centro a la vista del párrafo 2, del artículo io, que establece que las normas relativas a los derechos fundamentales y a las libertades de esta Constitución se interpretarán de conformidad con la Declaración de Derechos Humanos y demás tratados y acuerdos internaciones sobre la materia.

Lo más curioso y anecdótico es que votaron a favor del texto de la ponencia -que concedía una garantía más reducida- la Unión de Centro democrático, el Partido Socialista Obrero Español y Minoría Catalana. El motivo de este voto a favor, a pesar de las discrepancias de fondo que se manifestaron durante los debates parlamentarios, lo tenemos que buscar en el acuerdo previo a que habían llegado los grupos políticos en la redacción del artículo 27 de la Constitución, el acuerdo giraba en torno a la constitucionalización de la libertad de enseñanza y su financiación. El articulo 27 tiene un extenso contenido de derechos y obligaciones, en el que como dice Puelles se buscó «un consenso de mínimos, un denominador común que fue posible porque, junto a coincidencias básicas, hubo concesiones por parte de los dos grandes bloques que representaban programas, ideologías e intereses distintos» ${ }^{\mathrm{I4}}$.

Con la libertad de enseñanza se trató de constitucionalizar el derecho de todos a crear y dirigir una enseñanza libre, y el derecho de los padres a escoger para sus hijos la educación que prefieran conforme a sus propias convicciones, y el deber del Estado de subvencionar conforme al principio de igualdad, que recoge el propio texto constitucional, el derecho a la educación. Frente a este planteamiento se proponía otro con un modelo único de escuela pública, como instrumento para asegurar la educación de todos en igualdad de condiciones, que debería gestionarse por la Administración Pública, con la colaboración conjunta de profesorado, padres, y de los propios alumnos.

El resultado final de esta pugna quedó plasmado en el artículo 27 de la Constitución. Se aceptó una enmienda al artículo io a instancia de los grupos parlamentarios de UCD, Socialistas y Progresistas independientes y con la airada oposición del PSOE, que vino a introducir un complemento fundamental para la plena comprensión de cuanto se afirma en el artículo 27. La enmienda consistió en añadir un párrafo segundo al artículo io, que obliga a interpretar las normas relativas a los derechos fundamentales y a las libertades que la Constitución reconoce, de conformidad con la Declaración Universal de Derechos Humanos y los Tratados y Acuerdos internacionales sobre las mismas materias ratificados por España. Esta enmienda resulta para mí fundamental puesto que la redacción del articulado de la Constitución quedaba muy ambiguo, y dejaba el derecho de los padres a la libre interpretación subjetiva, mientras que con la aplicación supletoria de los Tratados y Acuerdos internacionales ratificados por España queda este derecho con una mayor protección ya que en éstos textos se recoge claramente el derecho de los padres a la elección de centro. Es el derecho que define Alzaga Villamil «el hecho de que la libertad de enseñanza sea calificada como una libertad de libertades ${ }^{15}$

El Partido Socialista aceptó el derecho de los padres a que sus hijos reciban la formación religiosa y moral de acuerdo con sus propias convicciones, aceptó plenamente la libertad de enseñanza, reconociendo un sistema educativo dual, público y privado, y aceptaron que los poderes públicos asumieran la obligación de ayudar a los centros privados siempre que reúnan los requisitos de la ley. Defendía también una educación obligatoria, general y gratuita El partido centrista de UCD aceptó que los poderes públicos garantizaran el derecho a la educación, y que la comunidad educativa (padres, profesores y alumnos) intervinieran en el control y gestión de los centros sostenidos con fondos públicos, defendía

${ }^{14}$ DE Puelles, M., «Política y educación: cien años de historia», Revista de educación, número extraordinario, Madrid, 2000, pp. 7-36.

\footnotetext{
${ }^{15}$ AlZaga Villamil, O., Por la libertad de enseñanza, Madrid: Tecnos, I983, p. 243.
} 
la libertad de enseñanza. Como dice Díaz Revorio «la causa de las peculiaredades del precepto que comentamos hay que buscarla en la elaboración de la Norma fundamental y en los debates que acompañaron a la misma. En aquel momento, se enfrentaban dos modelos educativos que, en sus extremos más radicales, pueden resumirse como "libertad absoluta de enseñanza y pluralismo escolar" (derecha) frente a "escuela pública, única, aunque pluralista" (izquierda); también cabría decir que, mientras la derecha se preocupaba más por la libertad de enseñanza, la izquierda se concentraba en el derecho a la educación obligatoria y gratuita ${ }^{16}$. Hay que tener en cuenta que fueron numerosas y variadas las definiciones que se pueden dar de la educación, como así las recoge Planchard ${ }^{17}$ y que cada uno de los integrantes del debate constituyente tenía una distinta, ahora bien como dice Puelles «la educación es un bien cultural y social sobre el que se proyectan diversos y variados derechos y libertades fundamentales» ${ }^{\mathrm{r}}$.

En el artículo i6 se recogió la posición de la iglesia, con el derecho a crear centros docentes y con el derecho de los padres a elegir el tipo de educación que deseen para sus hijos. Con la oposición del representante socialista Gregorio Peces-Barba, quién abandonó la ponencia el 7 de marzo de I978. Cuando se estuvo a punto de cerrar un pacto entre UCD y AP, el gobierno cambia de aliados en el pacto y busca un pacto con el PSOE, acuerdo al que se unirían el resto de partidos políticos, con lo que se logró el consenso final. Se aprueba en un primer momento un Anteproyecto de Constitución con un art. 28, pero éste en el Congreso es objeto de enmiendas por parte de los miembros de la Comisión de Asuntos Constitucionales y de Libertades Públicas. Así en el apartado I junto al «derecho» se añade también el «deber a la educación», el 3 que estaba redactado «los poderes públicos garantizan el derecho que asiste a los padres para que sus hijos reciban la formación religiosa y moral que está de acuerdo con sus propias convicciones» que modificado «los padres tienen derecho a que sus hijos reciban la formación religiosa y moral que esté de acuerdo con sus propias convicciones». En el art. 4 que recogía: «la enseñanza básica es obligatoria y gratuita» queda modificado por «la ley determinará el nivel de educación obligatoria y gratuita». En el art. 6 que recogía «Se reconoce a las personas físicas y jurídicas la libertad de creación de centros docentes, dentro del respeto a los principios constitucionales», queda así «se reconoce a las personas físicas y jurídicas la libertad de establecer y dirigir centros docentes dentro del respeto a los principios constitucionales».

Posteriormente la Comisión de Asuntos Constitucionales y de Libertades Públicas introdujo importantes modificaciones, desapareciendo el apartado $\mathrm{I}^{\circ}$ del artículo 27 la mención al «deber de la educación» añadiéndose el reconocimiento expreso de la libertad de enseñanza. Se introduce también en el apartado 7 una remisión a la ley para que sea ésta la que establezca la forma de intervención en la gestión y control de los centros docentes sostenidos con fondos públicos. El texto aprobado por la Comisión permanecerá invariable en su paso por el Congreso y por el Senado, fruto del consenso. Una de las modificaciones más importantes fue la introducción en la Comisión del Senado del artículo 27 de un apartado 2, «las normas relativas a los derechos fundamentales y a las libertades que la Constitución reconoce, se interpretarán de conformidad con la Declaración Universal de Derechos Humanos y acuerdos internacionales sobre las mismas materias ratificados por España». Este apartado resulta para mi clave a la hora de interpretar los derechos y libertades fundamentales en materia educativa, si bien ya se establece en el texto constitucional que los procedimientos de incorporación a nuestro ordenamiento jurídico de la Declaración Universal de Derechos Humanos y de los tratados internacionales. Este artículo fue introducido por iniciativa de la UCD como garantía frente a una interpretación restrictiva de la libertad de enseñanza y de la libertad de crear centros docentes privados.

\footnotetext{
${ }^{16}$ DíAZ ReVorio, F.J. «El derecho a la educación», Anuario Parlamento y Constitución 2, I998, p. 269.

${ }^{17}$ Planchard, E. La pedagogía contemporánea, trad. De García Hoz, Madrid, I969, pp. 29-30.

${ }^{\mathrm{I} 8}$ DE PUELLES, M. obra citada.
} 
Lamentablemente ese consenso que se logró entre nuestros padres constituyentes no ha tenido una continuidad, puesto que no ha tenido continuidad ya que se ha producido una pluralidad de leyes educativas.

\section{El contenido del derecho}

Nuestra Constitución establece con bastante nitidez la titularidad del derecho a la educación, asimismo en la mayor parte de los textos internacionales hay una alusión a padres y tutores, por tanto se puede deducir que se refiere a niveles de enseñanza en el que los hijos son menores de edad, hasta cierto punto es lógico puesto que más importante debe ser la elección del tipo de educación cuando menor es la edad. Si bien yo entiendo que este derecho se tiene que considerar como una derivación del reconocimiento de la libertad de enseñanza, que conlleva una doble extensión, la libertad en cuanto al ejercicio de la tarea educativa y la libertad en cuanto al derecho que todos tenemos a recibir la educación, no en su sentido de derecho social de prestación, sino en el de libertad en el acceso a la educación, con este planteamiento también la educación en la universidad se debe basar en el principio de libertad, también los mayores de edad son titulares de este derecho frente al Estado.

Es un derecho público subjetivo de libertad y no un derecho de prestación, por tanto es un derecho a elegir entre los centros educativos existentes. Conforme a su naturaleza jurídica de derecho de libertad, los padres tienen el derecho a elegir centros distintos a los creados por el Estado, entre todos aquellos centros creados al amparo de la libertad de enseñanza, como es lógico esta libertad de elección será dentro de la oferta educativa existente en el momento de la elección, y que cumplan los requisitos que establezcan los poderes públicos.

Es un derecho no a exigir una prestación de servicios, sino ante un derecho para impedir actuaciones que limiten la libertad de escoger, que impongan un modelo educativo.

Una forma de privar la libertad de elección de centro educativo es la de sustituir la financiación pública de la gratuidad por la prestación pública de la educación, en régimen de gratuidad, como así lo afirman Garcés San Agustín y Bermejo Vera «de la configuración del derecho a la educación como derecho fundamental no cabe predicar la gratuidad de los sistemas públicos constituidos para su prestación, y si la exigencia de poner en funcionamiento los mecanismos destinados a asegurar la igualdad material de todos los ciudadanos en el acceso a dichos sistemas» ${ }^{19}$.

El derecho a elegir centro docente se fundamenta en la libertad de enseñanza, de este principio deriva también el derecho de los padres a elegir la formación religiosa y moral que desean para sus hijos. El derecho de los padres se refiere no sólo a la enseñanza de la religión, sino también a la orientación filosófica, pedagógica e incluso organizativa del centro, la libertad de elección se enriquece.

Los únicos límites que se pueden imponer a esta elección, ya sea un centro público o privado, es el respeto a los principios democráticos de convivencia, los derechos y libertades fundamentales y el libre desarrollo de la personalidad del alumno, que son objetivos de la educación, según el artículo 27.2 de la Constitución Española, derecho que poseen todos los miembros de la comunidad escolar. O sea que el tipo de educación elegida

I9 Garces SAn AgUSTIN, A. Derecho Administrativo social y Bermejo VerA J. en Derecho Administrativo, parte especial, Zaragoza: Kronos, I991, p. 628. 
ha de adecuarse a las exigencias constitucionales sobre los fines y objetivos de la educación, en este sentido cualquier irregularidad en los centros escolares que no respeten estas condiciones implicarían su no autorización y la rescisión de su autorización.

Otro límite estaría en el ejercicio del derecho en los centros financiados con fondos públicos ( sean públicos o concertados) el cual queda limitado, en los supuestos de exceso de demanda de plazas, a que los criterios de selección sean objetivos e impuestos por la ley, y un control por parte del Estado y por parte de la comunidad escolar.

Otro límite estaría en incluir la obligación de evitar medidas o políticas que fomenten la discriminación dentro de la enseñanza, respetando el art. I3.I del Pacto Internacional de Derechos Económicos, sociales y culturales en una sociedad libre, en que se favorezca la comprensión, la tolerancia y la amistad entre todas las naciones y entre todos los grupos raciales, étnicos o religiosos.

El derecho de los padres a elegir el tipo de educación que deseen para sus hijos, tiene las garantías genéricas establecidas para la totalidad de los Derechos Fundamentales y Libertades Públicas. Los procedimientos tendrán las garantías que reconoce el Art. 8I de la Constitución en cuya virtud deberán revestir la forma de leyes orgánicas «las relativas al desarrollo de los derechos fundamentales y libertades públicas», normas que habrán de respetar siempre el contenido esencial de los derechos constitucionales, conforme al Art. 53.I.

Ha sido importante la inclusión que realizó la Ley Orgánica del Tribunal Constitucional en su disposición transitoria $2^{\mathrm{a}} .2$ por la que ha quedado subsanada la laguna legal que excluía los derechos educativos de la protección de la Ley 62/1978, de 26 de diciembre, sobre protección jurisdiccional de los derechos fundamentales de la persona.

Al consagrar el derecho de los padres a la elección de centro educativo se está salvaguardando el ámbito de la libertad ideológica sobre el que recae la actividad educativa.

El derecho a la educación se reconoce en el marco de los principios que inspiran el ordenamiento jurídico español, es decir de los derechos inviolables de la persona, por tanto como advierte Gallego Anabitartes «no es necesario construir el concepto de libertad de enseñanza como garantía institucional con respecto al derecho a la educación ${ }^{20}$.

Además de todas las garantías internacionales que están recogidas en los textos internacionales. Existen en mi opinión dos corrientes doctrinales: la que entiende que el derecho de los padres a elegir la formación religiosa y moral que desean sus hijos es un derecho que deriva del derecho a la libertad de enseñanza y los que no consideran este derecho como parte de la libertad de enseñanza. Como afirma Valero ${ }^{21}$ en opinión que comparto expresiones como las contenidas en el art. 26.3 de la Declaración Universal de Derechos Humanos y en no pocas legislaciones nacionales, aparte de expresar una convicción o un acuerdo social, sancionándolo con la fuerza de la Ley, están proclamando un principio, cuyo fundamento está fuera de las declaraciones y de las leyes y cuya fuerza obligatoria no deriva de ellas ni de la convicción social, sancionándolo con la fuerza de la ley, están proclamando un principio, cuyo fundamento está fuera de las declaraciones y de las leyes y cuya fuerza obligatoria no deriva de la convicción social, que las sustenta, sino de las exigencias de la naturaleza misma y de la dignidad de la persona humana.

${ }^{20}$ Gallego AnABitarte, A., «Derechos fundamentales y garantías institucionales: una recepción jurídico-doctrinal», Estudio preliminar al libro de DÍAZ LEMA, J.M. Los conciertos educativos en el contexto de nuestro derecho nacional, y en el derecho comparado, Madrid: Ed. Pons, I992, p. 38.

${ }^{21}$ VALERO, U., «Libertad de enseñanza», Razón y fe 944-945, Madrid, 2006, pp. 162-163. 
Parte de la doctrina opina que del principio de libertad de enseñanza deriva el derecho de los padres a elegir la formación religiosa y moral que desean para sus hijos. Como dice el Catedrático Martínez de Pisón «si hablamos de la libertad de enseñanza hacemos referencia a un derecho de autonomía, estamos ante un derecho de la primera generación, ante un derecho civil» ${ }^{22}$.

Los derechos de autonomía se caracterizan por proteger un ámbito de libertad exento de las injerencias de los poderes públicos. Estos derechos tienen un ámbito en el que sus titulares ejercen su libertad sin ningún tipo de impedimento y sin que se les pueda someter a ninguna coacción, uno es libre cuando no es coaccionado, puede decidir y elegir libremente, se trata de un concepto de «libertad negativa».

Como manifiesta Prieto Sanchis «la distinción entre derechos de autonomía y derechos de prestación proviene de la dogmática francesa» ${ }^{23}$. Por tanto son derechos de autonomía basados en el concepto negativo de la libertad tanto la libertad de enseñanza como el derecho de los padres a escoger para sus hijos el centro cuyo ideario se adecue a sus convicciones religiosas o filosóficas, no pudiendo los poderes públicos interferir en el libre derecho a la elección, se trata por tanto de poner unos límites a las actuaciones de los poderes públicos. Es un derecho que pese a carecer de reconocimiento constitucional expreso, se deriva del principio de libertad de enseñanza y del reconocimiento del derecho a la educación. Algún autor como Fernández-Miranda afirma categóricamente «que el reconocimiento del derecho en el artículo 27 y el contenido del articulo 53 dejan escaso margen a la duda. No parece lícito argumentar con la naturaleza material del derecho como derecho social de prestación para oponerla a la voluntad constitucional de configurarlo como un derecho que vincula a todos los poderes públicos» $»^{24}$.

En mi opinión el derecho del Art. 27.3 es un derecho público subjetivo de todos los titulares del derecho a la educación en la medida en que puede exigirse de los poderes públicos que la programación de la enseñanza incluya las materias que sean conformes a sus propias convicciones.

Como dice Burdeau en opinión que comparto el derecho a la educación entraña no solamente las facultades propias de una libertad de hacer o no hacer o de cómo hacer con el consiguiente poder jurídicamente protegido de excluir toda clase de intromisiones e interferencias restrictivas erga omnes, sino también y sobre todo un poder de exigir a otros unas prestaciones positivas dirigidas a producir el resultado de la instrucción educativa. ${ }^{25}$ Esta línea es la que han seguido autores de la doctrina francesa como Colliard, quien engloba la denominación de libertad de enseñanza, dentro de la consideración de la libertad de pensamiento ${ }^{26}$.

En mi opinión nuestra Constitución no proclama explícitamente el derecho a la libre elección de centros educativos, además de deducirse del reconocimiento expreso que hace de la libertad de enseñanza, entendido como un derecho de autonomía, podríamos decir que es un ámbito de autonomía en el que los padres tienen derecho a ejercer su libertad, si bien es un concepto negativo de la libertad, en cuanto a que el Estado no puede

\footnotetext{
${ }^{22}$ MARTíneZ De Pisón, J., Política del Bienestar: Un estudio sobre los derechos sociales, Prol. de M. CAlvo, Tecnos/Universidad de La Rioja, I998, p. 63.

${ }^{23}$ PRIETO SANCHIS, L., Estudios sobre derechos fundamentales, Madrid: Debate, I990, p. I9I.

${ }^{24}$ FERnANDEZ MiRANDA y CAMPOAMOR, A., De la libertad de enseñanza al derecho a la educación. Los derechos constitutivos en la Constitución, Madrid: Ed. Centro de Estudios Ramón Areces, I988, p. 34 .

${ }^{25}$ BURdeAU, G., Les libertés publiques, París : L.G.D.J., I972, $4^{\text {a }}$ edición, pp. 2I-23.

${ }^{26}$ Colliard, C.A., Libertés publiques, París: Dalloz, I98, capítulo $3^{\circ}$, Título II.
} 
impedir ni limitar mis decisiones, debe respetarlas. Además el derecho a la libre elección de centro tiene un contenido esencial comprendido dentro del derecho fundamental a la educación que se contempla en el Art. 27.I de nuestra Constitución, artículo que se ha interpretado conforme a la Declaración Universal de Derechos humanos y los Tratado y Acuerdos Internacionales sobre la materia ratificados por España.

Comparto la opinión de Castillo cuando dice que a diferencia de la concepción tradicional de libertad de enseñanza entendida simplemente como la libertad de creación de centros docentes se la debe concebir como conformada la ya citada libertad de creación de centros docentes y consecuentemente la libertad de dotarles, el derecho de los padres para que sus hijos reciban la formación religiosa y moral que esté de acuerdo con sus propias convicciones $^{27}$.

De la misma opinión es Musoles cuando dice «una de las facultades dimanantes del derecho docente de los padres es la posibilidad de elegir centro en el panorama plural español. El modo de ejercer el derecho de los padres a elegir una determinada formación religiosa y moral para sus hijos, y por tanto, la manera de darse la posibilidad a los padres de que escojan una determinada formación moral o religiosa es ofreciéndoles a la vez la oportunidad de elegir un determinado centro en el cual educar a sus hijos» ${ }^{28}$.

La doctrina en general así como la legislación de desarrollo constitucional incluye dentro del contenido jurídico de la libertad de enseñanza el derecho de elección de centro docente en el que se desea recibir enseñanza, y es que como ha manifestado el Tribunal Constitucional «es obvio que la elección de centro docente es un modo de elegir una determinada formación religiosa y moral» ${ }^{29}$, hay que tener en cuenta que se trata de un derecho recogido en una norma internacional, artículo 13.3 del Pacto Internacional de Derechos Económicos, Sociales y Culturales que establece «que los Estados Partes en el presente Pacto se comprometen a respetar la libertad de los padres y, en su caso de los tutores legales, de escoger para sus hijos o pupilos escuelas distintas de las creadas por las autoridades públicas, siempre que aquellas satisfagan las normas mínimas que el Estado prescriba o apruebe en materia de enseñanza, y de hacer que sus hijos o pupilos reciban la educación religiosa o moral que esté de acuerdo con sus propias convicciones» y que en virtud de lo dispuesto en el artículo io.2 de la Constitución Española puede trasladarse al ordenamiento jurídico español.

López Muñiz opina que «diferenciando el derecho a la educación, de la libertad de enseñanza, deducida esta libertad del reconocimiento expreso, y asumiéndolos como dos derechos distintos y autónomos colocan el derecho de elección de centro como parte del contenido esencial del derecho a la educación» ${ }^{30}$. Coincido plenamente con esta opinión doctrinal al deducir de la libertad de enseñanza el reconocimiento del derecho a la libre elección de centros educativos distintos de los públicos en todos los niveles de la enseñanza.

La Constitución Española establece una determinada capacidad jurídica al reconocimiento de los derechos fundamentales y así diferencia los de la sección primera y la sección segunda del capitulo segundo, siendo el derecho a la educación como lo clasifica

\footnotetext{
${ }^{27}$ CASTILlO, L. «La dimensión subjetiva o de libertad del derecho a la educación», Revista Persona $Y$ Derecho 50, Pamplona, 2004 .

${ }^{28}$ Musoles, M.C., «El derecho de los padres a la educación religiosa de sus hijos en la legislación española», Actualidad Administrativa i3, abril ı988, p. 7ı6.

${ }^{29}$ Fundamento jurídico $8^{\circ}$ de la Sentencia del Tribunal Constitucional 5/1981.

$3^{\circ}$ MARTíneZ LÓPEZ-MUÑIZ, J.L., «La educación en la Constitución Española (Derechos fundamentales y libertades públicas en materia de enseñanza», Persona $y$ derecho 6, Pamplona, I979, pp. $246-248$.
} 
García de Enterría «un típico derecho-prestación al que se le reconoce la operatividad fundamental de los de la sección primera» ${ }^{31}$.

Una vez que son asegurados por el Estado unos mínimos contenidos comunes en los diversos niveles de la enseñanza, la Administración ha de garantizar el que cada cual pueda elegir la educación correspondiente a su nivel en el establecimiento que mayor confianza le merezca y también como parte del derecho fundamental a la educación afirmado en el primer inciso del Art. 27.I, en mi opinión este derecho debe ser garantizado mediante una mayor protección en esta materia, teniendo en cuenta la importancia que tiene para el pleno desarrollo de la personalidad humana, sobre todo en los primeros años de vida, todo ello dentro de una coherencia, que permitan adaptar la educación, partiendo de las convicciones vividas y comunicadas en el seno del ambiente familiar. Al examinar el Art. 27.3 de la Constitución yo creo que existe una limitación a la libertad de enseñanza, reduciéndola exclusivamente a la posibilidad de que los padres elijan para sus hijos la formación religiosa y moral que deban de recibir, como dice Ortíz Díaz «El Art. 27.3 implica en la práctica una recorte, y en cierto modo una "trampa" del derecho de los padres a escoger el tipo total de educación para sus hijos» ${ }^{32}$.

Otra parte de la doctrina, entre la que se encuentra Embid Irujo no considera este derecho de libertad de elección de centro escolar como parte de la libertad de enseñanza, sino en palabras del autor «parte del haz de derechos que puedan tener los padres en las condiciones legales que se determinen y que nunca podrá ser emanación de la libertad reconocida en el Art. 27.I de la CE» ${ }^{33}$. Discrepo de la opinión de este autor cuando dice que la incorporación del derecho de los padres a elegir el tipo de educación «no se produce a nivel constitucional, sino de norma ordinaria $»^{34}$, se basa este autor en las postulaciones de Haeberle y de Tomandl, quienes plantean la positivación de los derechos sociales por vía de ley ordinaria y no constitucional. Discrepo de la opinión de Embid Irujo, pues está negando el derecho a elegir el centro de enseñanza, derecho con rango constitucional, previsto en el Ordenamiento internacional, de aplicación en España por mandato del Art. Io.2 y 96 de la CE, no teniendo en cuenta este autor que las normas contenidas en los tratados internacionales que pasan a formar parte del Ordenamiento interno pero no establece su rango en dicho ordenamiento, éste dependerá de los requisitos formales y, de los contenidos materiales de tales normas.

Tampoco estoy de acuerdo cuando se refiere a que el derecho de los padres a elegir la educación de los hijos, lo considera un derecho autónomo, puesto que yo considero que el derecho a la educación no puede entenderse al margen de la libertad de Enseñanza. ${ }^{35}$

Existen opiniones como la de Sánchez Agesta quién mantiene una postura discrepante respecto a Embid Irujo cuando dice «sólo indirectamente, por extensión del derecho a escoger una formación moral y religiosa y por interpretación de los pactos internacionales, puede hablarse de la libertad de aprender, como libertad de los padres o de

${ }^{31}$ García de Enterría, E. y Fernández, T.R., Curso de Derecho Administrativo II, Madrid: Civitas, I999, $3^{\text {a }}$ ed., pp. 60-6I.

$3^{32}$ ORTíz DíAZ, J. La libertad de Enseñanza, Málaga, ı980, p. 249.

33 Embid IRUJO, A., «La enseñanza privada en España: consideraciones sobre su problemática actual en el marco de la política Europea sobre educación», Revista de Administración Pública I42, enero- abril I997, p. 87.

34 Embid IRUjo, A., «El contenido del derecho a la educación», Revista Española de Derecho Administrativo 3I, I98I, p. 672.

${ }^{35}$ Embid IRUjo, A., Las libertades en la enseñanza, Madrid: Tecnos, , I983, p. 243. 
los tutores legales para elegir para sus hijos establecimientos de enseñanza que no sean los mantenidos por los poderes públicos» ${ }^{36}$.

El defender la libertad de elección de centro implica la defensa del derecho a la libertad de creación de centros docentes, siendo éste un derecho que también corresponde a los padres, quienes pueden asociarse, constituir un colegio que sea conforme a sus convicciones, que sean centros educativos de iniciativa social. La razón de ser de la libertad de creación de centros docentes está en favorecer que exista una pluralidad en el sistema educativo, que los padres tengan una pluralidad de posibilidades de elección. Autores como Alzaga se definen a favor de una concepción amplia de la libertad de elección de los padres, englobando también los aspectos religiosos y filosóficos ${ }^{37}$.

Yo considero que el derecho de los padres a elegir el tipo de educación que deseen para sus hijos conforme a sus convicciones religiosas, filosóficas, etc., y el derecho a la libertad de elección de centro derivan del derecho de libertad de enseñanza ya que constitucionalmente así está prevista para favorecer la pluralidad en el sistema educativo a través del ofrecimiento de una pluralidad de posibilidades de elección de los padres, si bien el hecho de poder elegir entre un centro de enseñanza y otro no supone de modo necesario el acceder a una plaza en el centro elegido, pues por una exigencia de ordenación del sistema educativo el acceso deberá estar sujeto al cumplimiento de unos requisitos, siempre que éstos no sean discriminatorios o impidan la aplicación del pluralismo en el sistema educativo. Para Menéndez Rexach el derecho a la educación no es únicamente un derecho social de prestación ya que «un típico derecho cuya efectividad no se asegura con la pasividad de los poderes públicos, sino que requiere la activa intervención de éstos, incluso aunque no se llegase a configurarlo como un servicio público, es decir, como una actividad de titularidad pública $»^{3^{8}}$. También en un sistema escolar plural, el ideario, entendido como definición filosófica y religiosa del centro educativo, es pieza clave en el ejercicio del derecho de los padres a elegir el tipo de educación; la relación entre ideario y derecho de los padres reside en que este derecho recae no sólo sobre aspectos didácticos o pedagógicos sino que, también se refiere a fines y objetivos de la educación recogidos en el ideario. Como dice Barrena en opinión que comparto la educación no es posible sin la referencia a valores, proyectos y actitudes fundamentales. ${ }^{39}$

El Tribunal Constitucional ha afirmado en la Sentencia que resolvió el recurso con la LODE en sentencia 51/85 que no es incompatible el derecho del titular de un centro concertado a la dirección con que deba contar en sus decisiones con el concurso del consejo escolar, siempre que quede a salvo su capacidad decisoria, entendido como una forma de manifestación de la libertad de enseñanza y de la creación de centros, y de la pluralidad educativa que ofrezca a los padres una mayor oferta educativa. Sin embargo autores como Suárez Pertierra son contrarios a lo declarado por el Tribunal Constitucional, y ponen en cuestión la posibilidad de la fijación del carácter propio del centro sostenido con fondos públicos, cuando manifiesta «Con respecto a los centros subvencionados, en concreto, parece inviable la fijación de un ideario en conformidad con la Constitución. (...) resulta contradictorio o, cuando menos, problemático que si padres, profesores y alumnos deben intervenir en su gestión, por mandato constitucional, se encuentren previamente comprometidos por una dirección impuesta de manera específica» ${ }^{4}$.

${ }^{36}$ SAnChez Agesta, I., Sistema político de la Constitución Española de 1978, Madrid, I980, p. I42.

${ }^{37}$ Alzaga Villamil, O., La Constitución Española de 1978 (Comentario Sistemático), Madrid, I978, pp. 257 y ss.

${ }^{38}$ MenÉndeZ ReXach, A., Proyecto docente e investigador, Valladolid, I99I, p. 236.

${ }^{39}$ BARRENA, J., «El Proyecto Educativo», Educación $y$ sociedad pluralista, Bilbao, I980, p. 74.

$4^{\circ}$ SuÁrez Pertierra, G., «Reflexiones acerca de la relación entre la libertad de enseñanza e ideario de centro educativo», Anuario de derechos humanos 2, I983, pp. 635-636. 
Con esta opinión no estoy nada de acuerdo, puesto que no se respeta el derecho ni de los alumnos ni de los padres, ni por supuesto el derecho del titular del centro a establecer un carácter propio y a dirigir el centro, y que me parece una limitación de la libertad escolar, y por tanto supondría un incumplimiento del deber que corresponde a los poderes públicos de garantizar el derecho a la educación en libertad.

Tampoco comparto la opinión de De Esteban y López Guerra cuando manifiestan que la Constitución prescribe, que es un deber primario de los poderes públicos suministrar puestos escolares públicos a todos los que pretendan su acceso a ellos. La ayuda a otros centros docentes es permitida, de acuerdo con el espíritu de la Constitución, sólo en un plano secundario, una vez satisfechas totalmente las necesidades de puestos escolares públicos. ${ }^{41}$ Yo entiendo que este no es el espíritu de la Constitución puesto que el derecho a la educación lo tienen también quienes no pretendan hacerlo efectivo en los centros públicos, y con este planteamiento no se les aseguraría. El legislador debe establecer unos requisitos para que los centros puedan beneficiarse de las ayudas públicas a la enseñanza, lo que no significa que tales requisitos sean contrarios al contenido esencial del derecho a dirigir el centro de enseñanza, como dice Fernández Farreres «las ayudas a los centros no podrán ser nunca ayudas de resultado, en el sentido de que no podrán llevar consigo la exigencia de una determinada organización del centro, más allá de la que obligue la efectividad de los derechos del resto de la comunidad escolar» ${ }^{42}$.

\section{Límites del derecho}

El derecho a la educación como derecho de prestación, tendrá como límites el derecho a que cada niño tenga derecho a la adjudicación de una plaza escolar en un centro docente, como ya sabemos, el art. 27 CE no sólo consagra un derecho de libertad (libertad de enseñanza), sino también un derecho de prestación (derecho a la educación en sentido estricto o derecho a la educación como derecho de prestación), de él surge necesariamente una obligación positiva para los poderes públicos de realizar las actuaciones precisas para que la prestación a la que se refiere, la educación, llegue en condiciones adecuadas a los ciudadanos, como muy acertadamente han recogido autores como Martínez López Muñiz y Martínez de Pisón. ${ }^{43}$ En otros términos, quedan obligados a garantizar la existencia y correcto funcionamiento del servicio educativo. Lo que, en definitiva, supone que la educación es servicio esencial porque la propia Constitución lo establece expresamente, y eso es algo que está más allá de la capacidad de decisión del legislador.

Otro límite estará en que se dediquen partidas presupuestarias a la educación por el Estado, ya que esa actividad es indispensable para la vida social, por lo que pesa sobre los poderes públicos una obligación de garantizar su prestación. Esto no implica que deba suministrarse directamente por el Estado, ni siquiera que tenga que correr con los gastos que su realización ocasione. Cabe perfectamente que esa actividad esencial sea correctamente prestada por la libre iniciativa privada, sin que tenga que verificarse, entonces, una intervención pública sobre la misma. En definitiva, el servicio esencial debe llegar necesariamente a los ciudadanos, lo que supone que los poderes públicos deben vigilar que así sea, interviniendo en caso de que sea necesaria su acción para que su provisión sea efectiva. Pero, en principio, el que un servicio sea esencial no condiciona su

\footnotetext{
${ }^{4 \mathrm{I}}$ DE ESTEBAn, J. y LÓPEZ GUeRRA, L., El régimen Constitucional español, cit., p. 335.

${ }^{42}$ FERnÁNDEZ FARRERES, G., «De nuevo sobre la subvención y su régimen jurídico en el Derecho español», Revista de Administraciones públicas II3, Madrid, I987, p. 73.

${ }^{43}$ MARTíneZ De Pisón, J.M., El derecho a la educación y a la libertad de enseñanza, Madrid: Dykinson, 2003, p. 63 y MARTíNEZ LÓPEZ-MUÑIZ, J.L., «La educación en la Constitución Española», Persona y Derecho 6, p. 235 .
} 
régimen jurídico, no obliga a que la Administración tenga que intervenir necesariamente para hacer posible su prestación, pues que esa intervención se produzca dependerá de las características concretas de cada servicio. Deben existir recursos suficientes para que se puede financiar el sistema educativo.

La segunda consecuencia que se deriva de la calificación de un servicio como esencial es que éste debe funcionar bajo determinadas condiciones, con mucha claridad y muy bien señaladas por Sendín García ${ }^{44}$. Está sujeto a un conjunto de leyes o principios básicos que garantizan su correcta prestación. Pues su carácter indispensable hace que no sea suficiente con garantizar su suministro, es además preciso que éste se produzca de forma adecuada. Concretamente es preciso que se lleve a cabo de forma regular (continuidad), a todos los ciudadanos (universalidad), en condiciones no discriminatorias (igualdad), con un nivel de calidad adecuado (calidad) y a un coste razonable (accesibilidad).

Otro límite es el de que los criterios de admisión para la adjudicación de plazas permita la posibilidad de escoger el centro deseado, objeto sobre el que gira este trabajo, por ello no puede haber un monopolio por parte del Estado. Efectivamente, la propia Constitución prohíbe la conversión de la educación en un monopolio de iure, denominación que recogen varios autores, entre ellos, Troncoso Reigada, Embid Irujo, Lorenzo Vázquez, Parejo Alfonso, Garrido Falla y Cosculluela Montaner ${ }^{45}$.

Los padres tienen el derecho de que a sus hijos se les adjudique una plaza en un centro docente, para ello deben existir plazas suficientes y en las diversas zonas con el objeto de que los padres sean libres a la hora de elegir y no se vean condicionados por requisitos restrictivos de los criterios de admisión para la admisión de plazas.

\section{El cheque escolar en el sistema educativo español}

El comienzo de los bonos escolares se remonta a mediados de la década de los 8o, los puso en práctica el Secretario de Educación estadounidense William Bennett, su interés fue motivado por una decisión de la Corte Suprema en I985, que negaba servicios sustitutorios para niños de bajos ingresos con desventajas educativas. Bennett trató de establecer un sistema especial de bonos para los pobres, a fin de que pudieran obtener educación donde les fuera posible, neutralizando la decisión de la Corte Suprema que

${ }^{44}$ La Ley: Revista jurídica española de doctrina, jurisprudencia y bibliografía 3, 2006, pp. I667-1676. Troncoso ReIgADA, A., «Dogmática administrativa y Derecho constitucional: el caso del servicio público», Revista Española de Derecho Constitucional 57, septiembre-diciembre de I999, p. I07, nota 47. EMbid IRUJO, A., La enseñanza en España en el umbral del siglo XXI, Madrid: Tecnos, 2000, p. 228, nota I3. LORENZO VÁZQUEZ, P., Libertad religiosa y enseñanza en la Constitución, Madrid: CEPC/BOE, 200I, pp. 59-60. PAREJO ALFONSO, L., «La autonomía de las universidades», Aspectos administrativos del derecho a la educación. Especial consideración de las universidades públicas, Madrid: CGPJ, 200I, p. 298. GARRIDO FAlLA, F., «¿Crisis de la noción de servicio público?», en CosCUlluELA MONTANER, L. (coord.), Estudios de Derecho Público Económico. Libro Homenaje al Profesor Martín-Retortillo, Madrid: Civitas, 2003 , p. 443.

45 Troncoso ReigadA, A., «Dogmática administrativa y Derecho constitucional: el caso del servicio público», Revista Española de Derecho Constitucional 57, septiembre-diciembre de I999, p. I07, nota 47. EMBID IRUJO, A., La enseñanza en España en el umbral del siglo XXI, Madrid: Tecnos, 2000, p. 228, nota I3. LORENZO VÁZQUEZ, P., Libertad religiosa y enseñanza en la Constitución, Madrid: CEPC/BOE, 200I, pp. 59-60. PAREJO ALFONSO, L., «La autonomía de las universidades», en Aspectos administrativos del derecho a la educación. Especial consideración de las universidades públicas, Madrid: CGPJ, 200I, p. 298. GARRIDO FALLA, F., «Crisis de la noción de servicio público?», en CosCULLUELA Montaner, L. (coord.), Estudios de Derecho Público Económico. Libro Homenaje al Profesor MartínRetortillon, Madrid: Civitas, 2003, p. 443. 
consideró que al ser prestado los servicios educativos por profesores de escuelas oficiales que ingresaban en escuelas religiosas, se producía una violación del precepto constitucional sobre una estricta separación entre Iglesia y Estado. El planteamiento del bono fue el de reivindicar una vuelta al sistema de precios en el mercado educativo, y por tanto la abolición de la educación «gratuita».

La fórmula del cheque o bono escolar fue también propugnada por Friedman, M. (I962) Premio Nobel de Economía, como fórmula para mejorar la eficacia de los sistemas educativos. Lo que, precisamente, plantea ya este autor es que, si bien es comprensible que los poderes públicos financien la educación básica y obligatoria, no parece tener justificación suficiente el hecho de que tales poderes públicos se erijan en gestores de los establecimientos educativos. Como alternativa, este autor propone que la Administración pública entregue a los padres de familia cupones o cheques de un cierto poder adquisitivo para cada hijo en edad escolar: estos cheques serían utilizables por los padres como medio de pago de la educación de sus hijos, y serían abonados a los centros escolares que los padres eligieran.

El derecho a la educación no existe plenamente si no existe un auténtico pluralismo escolar, a dicho pluralismo se puede llegar mediante la implantación del cheque escolar, también denominado bono escolar, que representa una suma de dinero, válida únicamente para comprar educación, y que se otorga a los padres de todos los niños en edad escolar. Es canjeable en la escuela elegida por la familia, el bono o cheque escolar podría representar una parte o la totalidad del costo de educar al niño en las escuelas públicas.

No parece lógico que por ejemplo las personas con más ingresos reciban los mejores frutos de un sistema de educación estatal financiado por medio de fondos públicos integrados por impuestos que pagan personas de bajos ingresos. Hay que tener en cuenta que los ingresos fiscales de los que se financia la educación no provienen únicamente del impuesto sobre la renta, sino que las personas con menos rentas también pagan por la educación cada vez que consumen leche, repostan gasolina, compran tabaco, etc. Al conceder los bonos a las familias de baja renta para que con ellos pudieran financiar la educación de sus hijos, alcanzando así la categoría de consumidores en el mercado junto con otras familias de mayores ingresos. Como señala Hernazgómez de Mateo «La verdadera subvención al consumidor debe ir al bolsillo del consumidor y no al establecimiento, porque las subvenciones al establecimiento pueden ir dirigidas y pueden limitar la libertad de elección» ${ }^{46}$.

Una de las posibles soluciones podría ser la de los denominados cheques o bonos escolares, ya que ofrece libertad a los padres para elegir el modelo educativo que desean para sus hijos mediante la transferencia de la cantidad que corresponde a sus hijos al centro educativo que ellos elijan. Al fin y al cabo, la Constitución establece que quién tiene derecho a la subvención no son los centros, sino los alumnos. El cheque escolar es la garantía de la total libertad

La primera estrategia a tener en cuenta es la desgravación fiscal. Los padres que eligen un centro no financiado directamente por el Estado pueden deducir de sus impuestos una parte o la totalidad de los gastos escolares.

La segunda solución clásica se conoce con el nombre de «bono o cheque escolar»: A los padres que eligen una escuela privada, se les conceden unos bonos por una cantidad calculada sobre un porcentaje del costo correspondiente del alumno en una escuela pública. El bono puede ser cobrado por los centros reconocidos. Dificultad que se agrava en las

\footnotetext{
${ }^{46}$ HeRnAzGomez DE MATEO, J.L., «Con el cheque eliges tú», en <http://www.chequeescolar.org> [consultado el 9-09-2006, 21:00 h.].
} 
familias de escaso poder adquisitivo, impidiendo la matriculación en el centro privado escogido. Pienso que los que se oponen al cheque escolar (o, si se prefiere, a la desgravación fiscal) se colocan en el campo de los adversarios de la libertad. Yo creo que con el cheque escolar se está defendiendo la libre elección de centro, la mejora de la enseñanza, la redistribución de los recursos públicos y una educación compensatoria, en la que se reduzcan las diferencias sociales. La ayuda escolar permite a los niños de familias menos favorecidas acudir a escuelas que, de otro modo, no estarían a su alcance.

Que se busque un sistema educativo de calidad, en el que coexistan instituciones públicas y privadas, entre las que los padres puedan libremente elegir entre cada uno de los proyectos educativos de cada centro. Si éstos quedan bien concretados podemos decir que la escuela está más próxima a los deseos de los padres, y por tanto a las necesidades de los alumnos. Si se les niega este derecho vulneraríamos algo muy íntimo, vital dentro de las decisiones que se deben tomar en una familia.

En un sistema de libertad de enseñanza, en el que los padres eligen la escuela de sus hijos, es toda la sociedad civil la que asume la responsabilidad educativa. Juzgar a los padres incapaces de tales decisiones es una grave y mala interpretación de los principios que rigen una democracia. ¿Por qué se les juzga incapaces de responsabilizarse en este campo, cuando lo son manifiestamente en otros aspectos de la vida social? Los padres ejercen plenamente su responsabilidad en la elección del centro escolar de sus hijos. El ejercicio de esta elección, que representa también una forma de supervisión de la calidad pedagógica de la escuela, es un acto de responsabilidad individual y cívica. En el profundo debate suscitado en torno a este tema han aflorado algunas de las ventajas que el sistema podría suponer, a saber:

- Reducción del gasto público, a la vez que mayor disponibilidad real de recursos económicos para los centros.

- Facilidad de ajuste a las necesidades de los clientes o usuarios de los centros.

- Acomodación del funcionamiento de los centros a las apetencias de los propios usuarios.

- Estimulación de la iniciativa de los centros para atraer alumnos y mejora de la calidad.

- Acomodación de los gastos reales de los centros a su funcionamiento concreto.

- Mejoría en los propios centros de la relación coste y resultados.

El cheque escolar supondría un o'6\% del total del gasto educativo de cada Comunidad Autónoma, yo considero que lo único que faltaría sería sembrar una concienciación social y política a favor de la libertad educativa, con un único objetivo que cualquier persona, con independencia de su nivel de renta pueda enviar a su hijo al centro que prefiera, es una herramienta a favor de la equidad y de la libertad en la que los más beneficiados serían aquellos con rentas más bajas.

\section{Conclusiones}

Las conclusiones principales son las siguientes: 
$\mathrm{I}^{\mathrm{a}}$. El derecho a la educación tiene dos vertientes inseparables: es un derechoprestación, que legitima para recibir enseñanza, y es un derecho-libertad, que obliga a respetar la libertad de los padres.

$2^{\mathrm{a}}$. La Constitución en su art. 27 de forma implícita configura a la educación como un servicio esencial, obligando a los poderes públicos a garantizar que su prestación llegue a todos los ciudadanos en condiciones adecuadas. Dicha calificación como servicio esencial sólo alcanza a las enseñanzas regladas. Si bien eso no impide que los poderes públicos decidan adoptar medidas respecto a las enseñanzas no regladas, que contaran únicamente con la garantía que establezca la norma que fija esas medidas.

El art. 27 CE configura, además, la Educación como un servicio público. Si bien esa calificación no puede ser entendida en el sentido tradicional, como un servicio público subjetivo, en cuanto el reconocimiento del derecho a crear centros docentes impide la formación de un monopolio de iure en el ámbito de la enseñanza. Sino que debe entenderse como la creación de un servicio público objetivo.

Ese servicio público será suministrado a través de centros públicos y centros privados concertados, que están sujetos a un conjunto de obligaciones específicas para satisfacer el interés públicos, que tiene como contrapartida la concesión de un conjunto de ventajas que le permitan desarrollar su función. En definitiva, operan en un régimen de servicio público.

Sin embargo, esa calificación como servicio público no se extiende a los centros privados no concertados, que actúan conforme a un régimen de mercado y no conforme a un régimen de servicio público.

Se debe entender, por último, que la Constitución obliga a que en la prestación del servicio educativo participe una red de centros públicos, pues sólo éstos ofrecen las garantías suficientes de neutralidad que el servicio público exige.

$3^{a}$. Los poderes públicos no tienen el derecho a educar a los ciudadanos, porque ese derecho corresponde a los padres, a quienes se ha de asegurar la libertad de decidir el tipo de enseñanza que desean para sus hijos, sin más límites que los impuestos por el ordenamiento constitucional: el respeto a los principios democráticos de convivencia y a los derechos y libertades fundamentales.

Además los alumnos tienen constitucionalmente reconocidos unos derechos, por tanto habrá que establecer un equilibrio entre el respeto por parte de este del carácter propio del centro por el que ha optado por decisión propia o de sus padres por ser conforme a sus convicciones, a su vez dicho carácter propio habrá de tener en cuenta el derecho a que se respete la libertad de conciencia del alumno, sus convicciones religiosas y morales y su integridad personal y moral, no se puede violentar forzosamente la conciencia o las convicciones subjetivas del alumno, teniendo todos estos derechos de rango constitucional un carácter de inviolable. Si bien el alumno y sus padres deben respetar las exigencias que objetivamente se deriven del proyecto educativo del centro por el que han optado y al que han optado libremente, debiendo respetarlo, siempre que este carácter propio sea conforme a la Constitución, y que por tanto no puede establecerse como coacción a su libertad de conciencia, ni a su libertad, ni a su dignidad personal, teniendo el alumno la obligación de no perturbar el derecho de sus compañeros, o de lo padres que por ellos lo han ejercido, a formarse desde tales convicciones.

$4^{\mathrm{a}}$. La reflexión sobre la libertad de enseñanza debe superar el viejo discurso que opone el sector privado al público ya que se trata, en definitiva, de reivindicar una libertad pública. Las palabras claves son: libertad de elección, responsabilidad subsidiaria del Estado y pluralismo. 
El derecho a la educación sólo se satisface plenamente cuando se cubren esas dos vertientes: cuando los poderes públicos aseguran la escolarización de todos y cuando respetan la libertad de creación y de dirección de centros privados -dotados por su titular de un carácter propio- y el derecho de los padres a elegir escuela para sus hijos, de acuerdo con sus convicciones o preferencias morales, religiosas, filosóficas y pedagógicas

Como ha subrayado el Tribunal Constitucional, la libertad de enseñanza se extiende también a los aspectos pedagógicos y a los de organización escolar. Del reconocimiento de la elección como derecho -absoluto y fundamental, además- no se deduce una negación de la pluralidad como valor. Al contrario, las tesis que defiendo exige que la educación esté presidida por la libertad y por la pluralidad. Lo cual exige -y es una obligación constatarlo una vez más- que todos los ciudadanos tengan la posibilidad de elegir el centro que desean para sus hijos. La libertad individual, unida a la pluralidad de la oferta, que debe estar suficientemente garantizada por los poderes públicos, son el instrumento necesario para garantizar la exigible igualdad de oportunidades.

Una sociedad democrática debe promover la libertad de los ciudadanos y de las familias. Para ello es necesario que se pase de un Estado asistencial a un Estado subsidiario, en el que en defensa del interés general, de la igualdad de oportunidades y la promoción de la libertad a través del pluralismo de instituciones educativas.

$5^{a}$. Debe existir un pacto sobre gasto educativo entre el Gobierno central y las CC.AAS., se necesita un acuerdo sobre calidad e igualdad educativa, una ley de educación que no dure una legislatura sino al menos un par de décadas, con todas las garantías de recursos humanos y financieros, que mejore nuestra competitividad y cohesión social y nos coloque en la primera línea de los países europeos.

$6^{a}$. La importancia del derecho a la educación lleva a destinar una parte de los impuestos de los ciudadanos a financiar la enseñanza, en beneficio de las familias con hijos en edad escolar. Los poderes públicos siguen ese mandato social y pueden hacerlo de modos muy diversos: en España se hace con un sistema de conciertos económicos con los centros privados; también se podrían establecer otras fórmulas que garanticen la igualdad de oportunidades y la libertad de elección por parte de las familias como podría ser el cheque escolar. 